\title{
No distance between disabled people and rehabilitation engineer in high-tech era
}

\author{
Li Gun* \\ Department of Biomedical Engineering, School of Electronics and Information Engineering, Xi'an Technological University, Xi'an, Shaanxi Province, China
}

\begin{abstract}
Traditional face to face diagnosis and treatment model has existed for thousands of years between doctors and patients. But now high technologies have brought people great convenience in many fields. When the disabled people concerned, many technologies such as internet, remote sensing, signal processing, Virtual Reality and so on, are already playing an important role in rehabilitation engineering. This paper introduces these emergency new technologies associated with the disabled people and engineers in recent years, which can eliminate the psychological and space distance between disabled people and rehabilitation engineer in high-tech era.
\end{abstract}

\section{Introduction}

The rehabilitation strategies are needed to optimize function and reduce disability of disabled people. Many public plans are developed in some countries [1]. And now lots of specialized institutions for the rehabilitation of disabled people have been established [2]. The disabled people is widely distributed [3], so many scholars are committed to provide a rehabilitation approach to them [4]. Remote rehabilitation is a combination of rehabilitation medicine, computer technology, internet technology, sensor technology, information processing technology, etc., it is a new rehabilitation resources with a new concept of rehabilitation, which can provide space for the further development of rehabilitation engineering technology [5]. Based on the realization of cross-regional rehabilitation services, remote rehabilitation is the integrated use of communication technology, remote sensing technology, remote control technology. Remote rehabilitation allows people to achieve rehabilitation cross the geographical area via the information exchange. The value of remote rehabilitation is also reflected in the fact that it can optimize the configuration of manpower and materials. In fact, for individuals with disabilities, rehabilitation affected by many factors such as their family, their mood, social environment [6], especially today's high technologies.

Rehabilitation engineers can hear the voice of distant people through the microphone and touch the distant people via embedded artificial sensors into skin to get the signal such as the surface temperature, moisture distribution of disabled people [7]. Rehabilitation engineers can also operate medical and rehabilitation equipment by the remote control system [8]. With the aid of a remote rehabilitation system, information interaction between rehabilitation engineers and disabled people can be more flexible, efficient and convenient [9]. In addition, other technologies, such as wearable technology [10], gait analysis technology [11], synchronous audio-visual technology [12] and so on have been already implicated in the field of remote rehabilitation engineering. In the following paper, several important high technologies for remote rehabilitation will be systematically analyzed via contacting the traditional rehabilitation engineering.

\section{Remote collecting, processing and transmission of physiological signals}

Acquisition, processing and transmission of physiological signals including visual data, tactile data, sound data, and so on, is the core issue of the remote rehabilitation system. There are some new technologies appear in this area such as the sensor-engineered glove (SEG), which is proved to be an automated, non-invasive, quick, and easy technique for evaluating for many disabilities, is already used in the practice of the remote rehabilitation [13]. Take anther example, a wheelchair for people with disabilities must be a suitable seat according the user's buttocks pressure distribution. So, remote rehabilitation data usually include 2D, 3D and multidimensional, collecting, processing and transmission of these data need new medical robots [14]. All these data are the basis for the designing of wheelchair as it is necessary to combine the moving images, the current physiological function of the disabled people, and the situation of nursing staff, and the environment for wheelchair use [15].

Micro electro-mechanical system is an automated and intelligent micro-system that combines with microelectronic signal processing and control circuits. Micro electro-mechanical system has many privileges including small size, low energy consumption, and so on. It is already used in the rehabilitation engineering such as transform surgical instruments into intelligent surgical instruments, drug injection system, and so on. The uses of micro electro-mechanical system made intelligent surgical instruments reduce the risk and time of surgery, shorten the patient's recovery time and reduce the cost of treatment [16].

Correspondence to: Li Gun, Department of Biomedical Engineering, School of Electronics and Information Engineering, Xi'an Technological University, Xian, Shaanxi Province, China, E-mail: ligun@xatu.edu.cn

Key words: disabled people, rehabilitation engineer, auxiliary technology, remote rehabilitation

Received: August 16, 2017; Accepted: August 30, 2017; Published: August 31, 2017 
Rehabilitation team members including rehabilitation physicians, physiotherapists, occupational therapists, prosthetics and orthopedic equipment, auxiliary equipment manufacturers, etc., all form a complete remote rehabilitation team. All team members need the physiological function data of the disabled people [17]. So some new data processing methods have been put forward, such as neuro-fuzzy approach is very important for real-time trajectory generation for robotic rehabilitation [18], hybrid data fusion technology is used in patient evaluation for their robot-assisted passive and active lower limb rehabilitation [19]. Two-dimensional, three-dimensional even the multidimensional data are commonly, there are some new technologies put forward for designing, maintenance and processing of these data, such as cloud computing and cloud storage [20], wireless sensor networks [21], and so on. All above technologies mentioned are playing an important role in remote rehabilitation, and these technologies combined with the rehabilitation engineer can be summarized as in Figure 1.

\section{Remote rehabilitation services and virtual reality training}

The development of electronic communication technology enables the remote rehabilitation system to provide a series of related rehabilitation services for disabled people. To date, remote technology has been used in related rehabilitation areas such as functional assessment, management of rehabilitation programs, selection of caregivers and remote counseling, etc, for the disabled people $[22,23]$. Remote rehabilitation has brought great benefits, especially in the field of long-distance health care. Long- distance health care provides the possibility of access to health care for disabled people in remote areas, allowing their family members to take care of them [24]. Most of the remote rehabilitation systems are visualized and made up of webcams, remote video conferencing, video telephony, networks, and web pages that can carry rich information [25].

Virtual Reality technology uses a computer system to create an experience virtual world. It provides a real-time simulation of the entity object changes through the helmet-mounted display, data gloves and other auxiliary sensing equipment to provide users with an observation on interactive three-dimensional interface. In this situation, users can directly participate in the system and explore the simulation object in the environment [26]. For the remote rehabilitation system, the virtual reality technology will make the rehabilitation training more efficiency, more scientific and interesting, making the training time funny, and the training effect is more significant [27]. The development of virtual

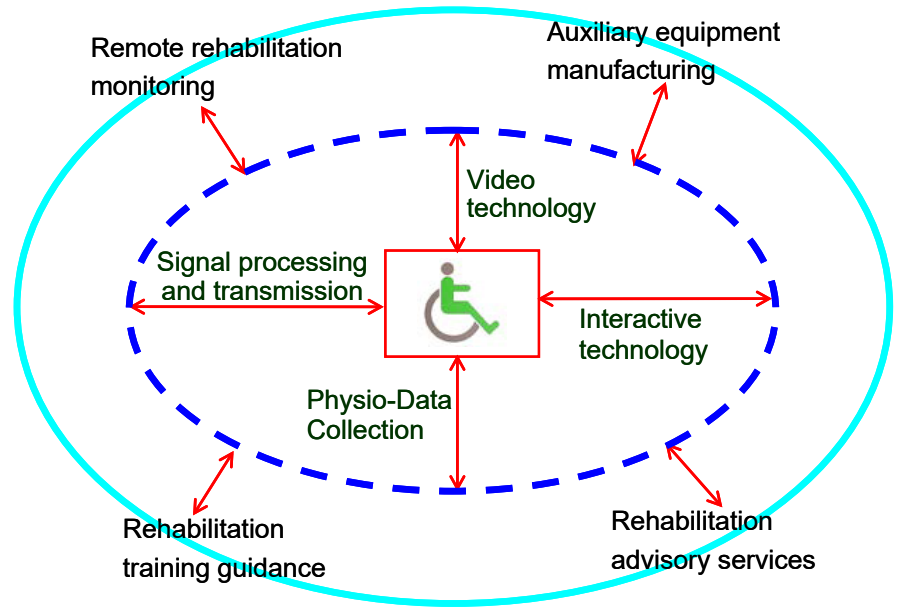

Figure 1. Inner (high-tech) circle and outer (engineer) circle with disabled people at core location. reality technology makes the interaction between man and machine become reality. A special person-machine interface allows the disabled person to successfully manipulate the computer or control related equipment to achieve self-care [28]. Combined with the development of communication technology, the development of rehabilitation and auxiliary engineering technology, the whole system enable the disabled people can be treated at home [29].

In addition, automatic control technology is also widely used in the field of remote rehabilitation engineering. Robust control of a hipjoint rehabilitation robot enables the patients with lower limb disability get the rehabilitation training via using the apparatus [30]. Artificial muscles could be used in the rehabilitation system for disabled people for providing their strength for training [31]. Famous 3D printing provides an efficient way for remote digitally manufacturing auxiliary technology [32]. All these new technologies eliminate the distance between the disabled people and the rehabilitation engineers.

\section{Conclusion}

The ultimate goal of remote rehabilitation is to make physically handicapped patients as much as possible to restore their independent and normal life via kinds of remote rehabilitation systems. With the applications of telemedicine technology from the initial high-tech field to the community and the family, home-based remote rehabilitation system has become a new trend in the development of rehabilitation technology in the future, which will make it more convenient for disabled people to get rehabilitation services, rehabilitation treatment. The rapid development of communications, computers, medical technology and human relentless efforts will eliminate the distance between the disabled people and the rehabilitation engineers, and enable disabled people to get corresponding rehabilitation services in any time and at any place.

\section{References}

1. NIH medical rehabilitation coordinating committee (2017) National institutes of health research plan on rehabilitation. Archives of Physical Medicine and Rehabilitation 98: e1-e4.

2. Reznick JS (2011) History at the intersection of disability and public health: the case of john galsworthy and disabled soldiers of the first world war. Disabil Health $J 4$ : 24-27. [Crossref]

3. Cheng YR (2015) Investigation and countermeasures on the health-promoting lifestyle of the disabled elderly in a rural area. Chinese Nursing Research 2: 107-109.

4. Mancisidor A, Zubizarreta A, Cabanes I, Bengoa P, Jung JH (2018) Kinematical and dynamical modeling of a multipurpose upper limbs rehabilitation robot. Robotics and Computer-Integrated Manufacturing 49: 374-387.

5. Xiao Y, Zhao K, Ma ZX, Li X, Qiu YP (2017) Integrated medical rehabilitation delivery in china. Chronic Diseases and Translational Medicine 3: 75-81.

6. Sharif F, Shoul A, Janati M, Kojuri J, Zare N (2012) The effect of cardiac rehabilitation on anxiety and depression in patients undergoing cardiac bypass graft surgery in Iran. BMC Cardiovasc Disord 12: 40-43. [Crossref]

7. Danilo P, Gianluca B, Alessia D, Iosto T, Matteo P, et al. (2014) A device for local or remote monitoring of hand rehabilitation sessions for rheumatic patients. IEEE Journal of Translational Engineering in Health \& Medicine 2: 1-11.

8. Atashzar SF, Polushin IG, Patel RV (2016) A small-gain approach for nonpassive bilateral telerobotic rehabilitation: Stability analysis and controller synthesis. IEEE Transactions on Robotics 33: 49-66.

9. Hamel M, Fontaine R, Boissy P (2008) In-home telerehabilitation for geriatric patients. Engineering in Medicine \& Biology Magazine IEEE 27: 29-37.

10. Sardini E, Serpelloni M, Pasqui V (2015) Wireless wearable t-shirt for posture monitoring during rehabilitation exercises. IEEE Transactions on Instrumentation \& Measurement 64: 439-448.

11. Jarchi D, Lo B, Wong C, Ieong E, Nathwani D, Yang GZ (2015) Gait analysis from a single ear-worn sensor: reliability and clinical evaluation for orthopaedic patients. IEEE Trans Neural Syst Rehabil Eng 24: 882-892. [Crossref] 
12. Tidoni E, Gergondet P, Fusco G, Kheddar A, Aglioti S (2017) The role of audio-visual feedback in a thought-based control of a humanoid robot: A BCI study in healthy and spinal cord injured people. IEEE Trans Neural Syst Rehabil Eng 25: 772-781. [Crossref]

13. Portaro S, Russo M, Naro A, Bramanti A, Bramanti P, et al. (2017) Advances in assessing myotonia: Can sensor-engineered glove have a role? J Neurol Sci 375: 3-7. [Crossref]

14. Daneshmand M, Bilici O, Bolotnikova A, Anbarjafari G (2017) Medical robots with potential applications in participatory and opportunistic remote sensing: a review. Robotics \& Autonomous Systems 95: 160-180.

15. Daponte P, Vito LD, Riccio M, Sementa C (2014) Design and validation of a motiontracking system for rom measurements in home rehabilitation. Measurement 55: 82-96.

16. Sharifi M, Behzadipour S, Salarieh H, Tavakoli M (2017) Cooperative modalities in robotic tele-rehabilitation using nonlinear bilateral impedance control. Control Engineering Practice 67: 52-63.

17. Polygerinos P, Wang Z, Galloway KC, Wood RJ, Walsh CJ (2015) Soft robotic glove for combined assistance and at-home rehabilitation. Robotics \& Autonomous Systems 73: $135-143$.

18. Martin P, Emami MR (2014) A neuro-fuzzy approach to real-time trajectory generation for robotic rehabilitation. Robotics and Autonomous Systems 62: 568-578.

19. Meng W, Liu Q, Zhou Z, Ai Q, Sheng B, Xie S (2015) Recent development of mechanisms and control strategies for robot-assisted lower limb rehabilitation. Mechatronics 31: 132-145.

20. Dogmus Z, Erdem E, Patoglu V (2015) Rehabrobo-onto: design, development and maintenance of a rehabilitation robotics ontology on the cloud. Robotics \& Computer Integrated Manufacturing 33: 100-109.

21. Hadjidj A, Souil M, Bouabdallah A, Challal Y, Owen H (2013) Wireless sensor networks for rehabilitation applications: challenges and opportunities. Journal of Network \& Computer Applications 36: 1-15.

22. Gialanella B, Ettori T, Faustini S, Baratti D, Bernocchi P, et al. (2016) Home-based telemedicine in patients with chronic neck pain. American Journal of Physical Medicine \& Rehabilitation 96: 327
23. Koochaki F, Sharifi I, Talebi HA (2016) A novel architecture for cooperative remote rehabilitation system. Computers \& Electrical Engineering 56: 715-731.

24. Tenforde AS, Hefner JE, Kodishwachs JE, Iaccarino MA, Paganoni S (2017) Telehealth in physical medicine and rehabilitation: A narrative review. $P m R$ 9: S51-S58. [Crossref]

25. Liu YM, Mathews K, Vardanian A, Bozkurt T, Schneider JC, et al. (2016) Urban telemedicine: The applicability of teleburns in the rehabilitative phase. $J$ Burn Care Res 38: e235-239. [Crossref]

26. Massetti T, Trevizan IL, Arab C, Favero FM, Ribeiropapa DC, Cb DMM (2016) Virtual reality in multiple sclerosis - a systematic review. Multiple Sclerosis \& Related Disorders 8: 107-112.

27. Pedreira dFE, Nm RDS, Pinto EB (2016) Therapeutic effect of virtual reality on post-stroke patients: Randomized clinical trial. J Stroke Cerebrovasc Dis 26: 94-100. [Crossref]

28. Trombetta M, Henrique PPB, Brum MR, Colussi EL, Marchi ACBde, Rieder R (2017) Motion Rehab AVE 3D: A VR-based exergame for post-strokerehabilitation. Computer Methods and Programs in Biomedicine 151: 15-20.

29. Yang WC, Wang HK, Wu RM, Lo CS, Lin KH (2016) Home-based virtual reality balance training and conventional balance training in parkinson's disease: A randomized controlled trial. J Formos Med Assoc 115: 734-743. [Crossref]

30. Guzmán CH, Blanco A, Brizuela JA, Gómez FA (2017) Robust control of a hip-join rehabilitation robot. Biomedical Signal Processing \& Control 35: 100-109.

31. Jobbágy B, Šimšík D, Karchňák J, Onofrejová D (2014) Robotic arm with artificial muscles in rehabilitation. Procedia Engineering 96: 195-202.

32. Lunsford C, Grindle G, Salatin B, Dicianno BE (2016) Innovations with 3-dimensiona printing in physical medicine and rehabilitation: a review of the literature. $P M R 8$ 1201-1212. [Crossref]

Copyright: (C2017 Gun L. This is an open-access article distributed under the terms of the Creative Commons Attribution License, which permits unrestricted use, distribution, and reproduction in any medium, provided the original author and source are credited. 